\title{
Relationship between Emotional-Behavioral Problems and Academic Achievement among Government and Private Schools Children
}

\author{
Aqeel Ahmed Khan ${ }^{1}$, Muhammad Shakir ${ }^{2}$, Ishrat Siddiqa Lodhi ${ }^{3}$
}

\begin{abstract}
This study was set out to compare the emotional behavioral problems and academic achievement among Government and Private school students. A sample of $(\mathrm{N}=239)$ children from government and private schools, including 120 girls and 119 boys, of ages 13 to 17 years were selected using convenient sampling technique. It was a quantitative research and a cross-sectional research design was used. The emotional-behavioral problems of students were checked by administering Strengths and Difficulties Questionnaire (SDQ) by Goodman (1997) and the students percentage of marks in the last examination was taken as their academic achievement. The results revealed a significant links of emotional-behavioral problems and academic achievement among overall government and private school children. Study further identified the significant difference in emotional differences in emotional behavioral problems and academic achievement among government and private school children. The study also explored that the academic performance was good in private school children as compared with government school children whereas, emotional behavioral problems of private school children was higher than government school children.
\end{abstract}

Keywords: Emotional Behavioral Problems, Academic Achievement, Government and Private school system

\section{Introduction}

Problems faced by children and adolescents can be separated into two broad categories as emotional and behavioral problems and also known as the externalizing and internalizing behavioral issues. The term internalizing refers to mind-set, uneasiness and dejection while externalizing is used for hostile and troublesome behavior (Achenbach\& McConaughy, 1991). The interpersonal troubles appeared in the form of grief anxiousness withdrawal and anxiety are recognized as emotional problems (Campbell, 1995) while troubles linked to

\footnotetext{
${ }^{1}$ Lecturer, Department of Applied Psychology, The Islamia University of Bahawalpur

${ }^{2}$ Lecturer, Department of Educational Training, The Islamia University of Bahawalpur

Email: shakir.iub@gmail.com

${ }^{3}$ Director (Academics), Higher Education Commission (HEC), Islamabad

Email: ishratsiddiqalodhi@gmail.com
} 
extrinsic actions replicate the child pessimistically acting upon the external atmosphere like aggression noncompliance and hyperactivity (Phares, 2003). These common terms are intricate to define and distinguish the psychological problems faced by adolescents.

Usually the school children face two broad types of problems such as emotional (Internalizing behavior) problems and (Externalizing behavior) problems. Internalizing behavior problems include withdrawal, apprehension embarrassment and nervousness. Most of the children's negative emotions are directed towards oneself rather than others in this problem behavior (Roeser, Eccles \& Strobel, 1998). These behavioral problems appeared as a consequence of extreme and overly strong self-regulation (Costello et al., 1996).A child retains and maintains these problems mutely which cause internal distress. This leads to anxiety, depression, social withdrawal and physical signs and symptoms (Bittner et al., 2007). Philosophers, educationists and researchers have divided internalizing behavioral problems as: apprehension somatic complaints, social withdrawal and phobias (Merrel et al., 2001). The DSM-5 (2013) has categorized emotional disorders into three major categories: mood disorders, anxiety disorders and somatoform disorders. The present study designed to address the problems faced by the school children as a substitute of classifying them into strict diagnostic categories.

\subsection{Objectives of Study}

1. To study the impact of emotional-behavioral problems and academic achievement of government and private school children

2. To examine the gender differences of emotional-behavioral problems among government and private school children

3. To compare the academic performance of government and private school children secondary level

4. To analyze the gender wise difference between emotional behavioral problems and academic achievement of overall children

\subsection{Hypotheses of Study}

$\mathrm{H}_{1}$. There is a significant impact of emotional-behavioral problems and academic achievement among government and private school children.

$\mathrm{H}_{2}$. There is a gender difference of emotional-behavioral problems among government and private school children.

$\mathrm{H}_{3}$. There is a significant difference of academic achievement among government and private school children.

$\mathrm{H}_{4}$. There is a significant gender wise difference between emotional behavioral problems and academic achievement among overall private school children. 


\section{Literature Review}

Problems related to children behavior incorporate aggression, anti-social behavior and conduct problems. Negative emotions are aimed at harming others (Roeser et al., 1998). Adolescents with behavioral troubles victim in conduct problems due to under-developed self-regulation skills (Costello et al., 1996). These behavioral troubles are more irritating, disturbing and bothersome particularly in school and home surroundings. Behavioral problems are observable and easy to diagnose (Merrell, 2003). Essential characteristics of these problems are aggression, anti-social behavior, conduct problems and hyperactivity (Zaln-Waxler et al., 2000). Quay (1986) divided the behavioral issues as: perceptual and attention deficit, hyperactivity, under socialized aggressive conduct disorder and socialized aggressive disorder. Diagnostic and Statistical Manual of Mental Disorder-5 (2013) has classified the behavioral issues into three categories: Attention Deficit / Hypersensitivity Disorder (ADHD), conduct disorder and oppositional defiant disorder. Behavioral issues are observable and easy to identify therefore, their occurrence is more frequent than emotional issues (Weisz \& Weiss, 1991).

Many researches proved that emotional and behavioral issues often lead to problems in educational domain particularly failure in presentation, high ratio of dropout students and low self-esteem (Pellegrini, 2007). Numerous researches carried out to check the prevalence of emotional and behavioral problems among adolescents. These studies suggested that $20 \%$ adolescents troubled with emotional behavioral issues and 6-19\% extremely distressed (Davis \& Spurr, 1998). In this connection, Costello et al. (1996) also reported high prevalence rate of psychiatric disorders in children. They pointed out $20.30 \%$ occurrence rate with high level of nervousness. Moreover, Liu et al. (1999) reported that $17.20 \%$ of children victim from mental problems. They also reported that comparatively boys faced more problems than girls. Prior, Virasinghe and Smart (2005) pointed out the high rate of behavioral problems in school children of ages 10-13 years. They also reported that the boys faced outstandingly greater troublesome behavior problems as compared with girls.

Researchers and educationists probed that government and private school environment, teaching methodology and culture matter for the children out comes or academic grades. Sunku (2014) conducted a research among Korean high school children to judge the academic achievement of government and private school children. The study revealed that the children studying in private schools were good in academic achievement as compared to those studying in government schools. Furthermore, results showed a difference in academic grades among the high school children as per their teaching methodology used in 
government and private school system. She proved that private school children are better in their academic grades as compared with government school children. Moreover, the study also concluded that girls were better in their academic grades as compared with boys.

\section{Research Methodology}

\subsection{Research Design}

The study was set out to compare the emotional behavioral problems and academic achievement of government and private school system. It was a quantitative research with cross-sectional research design.

\subsection{Sample of Study}

The students of $9^{\text {th }}$ and $10^{\text {th }}$ grade were selected form government and private schools from Multan having age of 13-17 years. The overall sample consisted of $\mathrm{N}=239$ students from government and private schools. Out of which $\mathrm{n}=119$ were boys and $\mathrm{n}=120$ were girls.

\subsection{Research Instrument}

To measure emotional behavioral problems a Strengths and Difficulty Questionnaire (SDQ) by Goodman (1997) was used. The academic achievement of the students was checked by using their current grade points.

\subsection{Independent and Dependent Variables}

In this research emotional behavioral problem was independent variable for academic achievement and for government and private school children. Similarly, academic achievement was independent variable for government and private school children.

\subsection{Inclusion and Exclusion Criteria}

Children of $9^{\text {th }}$ and $10^{\text {th }}$ classes studying in government and private schools having age limit of 13-17 years were included in this research. The students who didn't meet the proposed criteria were excluded from this research

Table 1

\section{Data Analysis \& Results}

Comparison of Academic Achievement and Emotional Behavioral Problems among Government and Private School Children

\begin{tabular}{clccccc}
\hline $\begin{array}{c}\text { Variables } \\
\text { including }\end{array}$ & Source of Variation & $S . S$ & Df & $M . S$ & $F$ & Sig. \\
\hline Academic & Between Groups & 7672.37 & 2 & 3836.19 & 11.98 & 0.00 \\
Performance & Within Groups & 75528.52 & 236 & 320.04 & & \\
& Total & 83200.88 & 238 & & & \\
Emotional and & Between Groups & 401.68 & 2 & 200.84 & 7.86 & 0.00 \\
Behavioral & Within Groups & 6033.48 & 236 & 25.57 & & \\
Problems & Total & 6435.16 & 238 & & & \\
\hline
\end{tabular}


Table 1 is depicting a comparison of academic achievement and emotional behavioral problems among overall government and private school children. The $\mathrm{P}$-Value of the academic performance is 0.000 which is less than 0.05 similarly the P-Value of emotional and behavioral problems is 0.000 which is also less than 0.005 .

Table 2

Comparison of Emotional and Behavioral Problems between Govt. and Private Institute Students

\begin{tabular}{cccccrrr}
\hline Institutes & $\mathrm{N}$ & Mean score & $\mathrm{SD}$ & Mean Diff & $\mathrm{t}$ value & $\mathrm{Df}$ & P-value \\
\hline Govt. & 120 & 11.64 & 4.79 & 0.543 & -0.807 & 237 & 0.421 \\
Private & 119 & 12.18 & 5.59 & & & & \\
\hline
\end{tabular}

$\mathrm{P}<0.05$

Table 2 is depicting that the average emotional and behavioral problem score of government school is 11.64 with std. deviation 4.79 and of private school students is 12.18 with std. deviation 5.59. So by means of comparison the private school students facing more problems as contrasted to government school students.

Table 3

Academic Achievement among overall Govt. and Private School Students

\begin{tabular}{cccccccc}
\hline Institutes & $\mathrm{N}$ & Mean score & $\mathrm{SD}$ & Mean Diff & $\mathrm{t}$ value & $\mathrm{Df}$ & P-value \\
\hline Govt. & 120 & 53.85 & 17.31 & 23.06 & -12.098 & 237 & 0.00 \\
Private & 119 & 76.91 & 11.56 & & & & \\
\hline
\end{tabular}

$\mathrm{P}<0.05$

Table 3 reveals that the academic performance of private school students is higher as compared to students of government schools.

Table 4

Comparison of Academic Achievement among overall Boys and Girls

\begin{tabular}{cccccccc}
\hline Gender & $\mathrm{N}$ & Mean score & $\mathrm{SD}$ & Mean Diff & $\mathrm{t}$ value & Df & P-value \\
\hline Boys & 119 & 57.53 & 19.36 & 14.34 & -7.050 & 237 & 0.00 \\
Girls & 120 & 73.07 & 14.33 & & & & \\
\hline
\end{tabular}

$\mathrm{P}<0.05$

The results predict good academic outcomes of girls as compared with boys of overall government and private schools children. 
Table 5

Comparison of Emotional and Behavioral Problems among overall Boys and Girls

\begin{tabular}{cccccccc}
\hline Gender & $\mathrm{N}$ & Mean score & $\mathrm{SD}$ & Mean Diff & $\mathrm{t}$ value & $\mathrm{Df}$ & P-value \\
\hline Boys & 119 & 11.71 & 4.95 & 0.394 & -0.585 & 237 & 0.550 \\
Girls & 120 & 12.11 & 5.45 & & & & \\
\hline
\end{tabular}

$\mathrm{P}<0.05$

The results depicted in table 5 shows that the emotional problems of girls are slightly higher than boys.

\section{Conclusion}

The outcomes of the present study revealed significant links of emotional-behavioral problems and academic achievement among government and private school students. On the basis of the results it concludes that the system of education plays a vital role in shaping the children emotions, behaviors and academic outcomes. In this research, the private schools children revealed a higher level of emotional and behavioral issues as compared to government school children. On the other hand it proved that the private schools children attained good grades as compared to government schools children. The girls are facing more emotional and behavioral problems as compared to boys. The academic performance of girls was good as compared to boys in overall study sample. Private school students are facing more problems as compared to government school students. Moreover, performance of private schools students was good as compared to the students of government schools. Hence, on the basis of the results it is concluded that school environment/system plays a vital role in attaining students' grades as well as emotions.

\section{Discussion}

The first hypothesis (H1) of the study was based on the assumption "There is a significant impact of emotional-behavioral problems and academic achievement among government and private school children. This hypothesis is accepted and the result revealed that the learning problems are higher in Government school students as compared to private school students; moreover, it is found that bullying is also higher in Government school students as compared to private school students. So hypothesis is accepted. Present findings are congruent with past study which also indicated that students of public high school experience bullying victimization twice as likely to be the students who belong to private school sectors (Riley, Cortines \& Jr, 1997). The second hypothesis (H2) of the study was based on the assumption "There is noticeable 
gender differences of emotional-behavioral problems among government and private school children. The hypothesis is accepted and the result revealed that gender playing a significant impact on emotional behavioral problems and academic achievement among government and private school children. Gender wise comparison of the study shows boys having higher level of learning problems as compared to girls, similarly boys having higher level of bullying as compared to girls. So according to the statistical analysis boys have higher rate of bullying and learning problems as compared to the girls. The results are similar with the past research conducted on high school students the results revealed that most of the high school students were engaged in bullying behaviour and the comparison showed that boys were engaged 8.4 times higher in violence and bullying as compare to girls (Turkmen et al, 2013).Consistent results are found in the past research which was conducted on U.S students. The research revealed that males reported more involvement in bullying as compared to females. Like as $7^{\text {th }}$ graders were more frequently involved in this phenomenon as compared to $8^{\text {th }}$ graders. Moreover, bullies and victims both were found highly depressed as compared to those students who were not involved in bullying (Steals \& Young, 2003). The third hypothesis (H3) was based on the assumption that "There is a significance difference of academic achievement among government and private school children". The result revealed that students having higher level of bullying having higher level of learning problems.

Similarly, results indicated the comparison which shows that students having higher level of bullying victimization have higher level of learning problems hence we conclude that there is positive relationship between level of depressiveness, level of bullying victimization and learning problems and level of depressiveness and learning problem is significantly high among bullied students. Similarly, the present findings are consistent with the past research conducted by Uba, Yaacob, \& Juhari (2010) it revealed that the positive and significant relationship was found between bullying and depressiveness among students. Similar research result showed that students who were frequently involved in bullying were more than twice likely to report depressive symptoms than those who were not involved in bullying (Shujja, Atta \& Shujjat, 2014). Another study revealed the consistent findings that bullying victimization is significantly high among students who had learning problems. It indicates that the prevalence rate of bullying victimization among elementary students was $24.5 \%$, similarly its rate in middle school was $34.1 \%$ and its rate among high school was $26.6 \%$. So it shows that bullying victimization rate is higher among students with learning problems (Black et al, 2012). The fourth hypothesis (H4) of the study was based on the assumption "There will be a significant gender 
wise difference between emotional behavioral problems and academic achievement among overall school children". The students demographic variables which were included in study were student's residence, student's age, grades, gender, academic performance, classes, parents literacy rate, student's with alive or died parents. Results indicated the facts and figures about the comparison of rural and urban students according to bullying level, depressiveness and learning problems. The comparison shows rural students having higher level of learning problems as compared to urban students.

Results show the comparison of students with alive and died parents according to bullying level, depressiveness and learning problems. Comparison shows students with died parents having higher bullying level as compared to students with alive parents. Like as the comparison shows with died parents have higher level of learning problems and depressive symptoms as compared to those students whose parents were alive. Comparison shows students with illiterate parents having higher bullying level as compared to students with literate parents. The present findings are consistent with the past research results(Uba, Yaacob, \& Juhari, 2010) which indicated that bullying victimization is more common and is practiced by boys especially who belong to rural areas school, more over such students belong to the families with lower socio-economic status. Similarly, one of the past research according to an international study revealed that every third student out of ten students was identified as involved in school bullying. Demographic variables and socio-economic status of those students also have great impact in fostering the bullying behaviour; such demographic variables may vary from, the parenting styles, parents' relationship to each other, different teaching styles, the environment of school and interpersonal peer relationship (Abbas, Ashiq \& Abbas, 2014).

\section{Recommendations}

Keeping in view the findings of study, it is recommended that the government should take some measures regarding the behavioral problems of the students. As the result revealed that the learning problems are higher in Government school students as compared to private school students, moreover it is found that bullying is also higher in Government school students as compared to private school students. So, the government should prepare policy guidelines for private schools and implement them strictly. The results of the study further explore that gender plays a significant impact on emotional behavioral problems and academic achievement among government and private school children. Gender wise comparison of the study shows boys having higher level of learning problems as compared to girls so, the teachers should teach civic education skills 
to the students and government should add the themes related to civic education in curriculum.

\section{References}

Abbas, N. D., Ashiq, U., \& Abbas, F. (2014).Assessment of School Bullying and Contributing Factors A Case of Punjab Pakistan. Journal of Applied Environmental and Biological Sciences, 4(7), 246-256.

Achenbach, T.M., \&McConaughy, S.H. (1996). Empirically based Assessment of Child and Adolescent Psychopathology. Practical application. Development clinical psychology and psychiatry, 13, 167.

Bittner, A., Egger, H. L., Erkanli, A., Costello, E.J., Foley, D.L., \& Angold, A. (2007). What do childhood anxiety disorders predict. Journal of Child Psychology and Psychiatry, and Allied Disciplines, 48(12), 1174-1183.

Black, J. J., Lund, M. E., Zhou, Q., Kwok, M. O., \& Benz, R. M. (2012).National prevalence rates of bullying victimization among students with disabilities in the united states. American Psychological Association, 27(4), 210-222.

Campbell, S. B. (1995).Behaviour problems in preschool children: A review of recent research. Journal of Child Psychology and Psychiatry, 36(1), 115119.

Costello, E .J., Angold, A., Burns, B. J., Stangl, D. K., Tweed, D. L., Erkanli, A., \&Worthman, C.M. (1996). The Great Smoky Mountains study of youth, goals, design, methods, and the prevalence. Achieves of General Psychiatry, 53, 1129-1136.

Davis, H., \& Spurr, P. (1998). An evaluation of a community child mental health service. Journal of Child Psychology and Psychiatry, 39(3), 365-376.

DSM-5 (2013). Diagnostic and Statistical Manual. American Psychological Association.

Goodman, R. (1997). The strengths and difficulties questionnaire: A research note. Journal of Child Psychology and Psychiatry, 38, 581-586.

Liu, X., Kurita, H., Sun, Z., \& Wang, F. (1999). Risk factors for psychopathology among Chinese children. Psychiatry and Neuroscience, 53, 497-503. 
Merrell, K.W. (2001). Helping students overcome depression and anxiety. New York: The Guilford Press.

Merrell, K.W. (2003). Behavioral, social, and emotional assessment of children and adolescents. London: Lawrence Erlbaum Associates, Publishers.

Pellegrini, W. D. (2007). School Non-attendance: Definitions, meanings, responses, interventions. Educational Psychology in Practice, 2(1), 6377.

Phares, V. (2003). Understanding abnormal child psychology. USA: John Wiley $\&$ Sons Inc.

Prior, M., Virasinghe, S., \& Smart, D. (2005). Behavioral problems in Sri Lankan school children. Social Psychiatry and Psychiatric Epidemiology, 40, 654-662.

Quay, H. R. (1986). Classification. In H.C. Quay \&Werry, J. S. (Eds.), Psychopathological disorders of childhood ( $3^{\text {rd }}$ ed.). New York: Wiley \&Sons.

Riley, W. R., Cortines, C. R., \& Jr, F. D. (1997). Public and private school how do they differ? National center for education statistics, (12), 1-39.

Roeser, R., Eccles, J., \& Strobel, K. (1998). Linking the study of schooling mental health: Selected issues and empirical illustrations at the level of the individual. Educational Psychologist, 33, 153 - 176.

Shujja, S., Atta, M., \& Shujjat, J. (2014). Prevalence of Bullying and Victimization among Sixth Graders with Reference to Gender, Socioeconomic Status and Type of Schools. Journal of Social Sciences, 38(2), 159-165. doi: 10.1080/09718923.2014.11893246

Steals, D., \& Young, J.(2003). Bullying and victimization: Prevalence and relationship to gender, grade level, ethnicity, self-esteem and depression, Adolescence, 38(152), 176-200.

Sunku, H. (2014). Effects of Public and Private Schools on Academic Achievement. Seoul Journal of Economics, 27(2), 137-147.

Turkmen, N. D., Dokgoz, H. M., Akgoz, S. S., Eren, B. N. B., Vural, P. H. \& Polat, O. H. (2013). Bullying among high school students.doi:https://www.ncbi.nlm.nih.gov/pmc/articles/PMC3865123/ 
Uba, I., Yaacob, N. S., \& Juhari, R. (2010). Bullying and Its' Relationship with Depression among Teenagers, J Psychology, 1(1), 5-14.

Weisz, J. R., \& Weiss, B. (1991). Studying the "deferability" of child problems. Journal of Consulting and Clinical Psychology, 59, 266-273.

Zahn-Waxler, C., Klimes-Dougan, B., \& Slattery, M. J. (2000). Internalizing problems of childhood and adolescence: Prospects, pitfalls, and progress in understanding the development of anxiety and depression. Development and Psychopathology, 12, 443- 466. 